\title{
Intraoperative Nerve Monitoring Can Reduce Prevalence of Recurrent Laryngeal Nerve Injury in Thyroid Reoperations: Results of a Retrospective Cohort Study
}

\author{
Marcin Barczyński • Aleksander Konturek • \\ Krzysztof Pragacz • Aleksandra Papier • \\ Małgorzata Stopa $\cdot$ Wojciech Nowak
}

Published online: 1 October 2013

(C) The Author(s) 2013. This article is published with open access at Springerlink.com

\begin{abstract}
Background The prevalence of recurrent laryngeal nerve (RLN) injury is higher in repeat than in primary thyroid operations. The use of intraoperative nerve monitoring (IONM) as an aid in dissection of the scar tissue is believed to minimize the risk of nerve injury. The aim of this study was to examine whether the use of IONM in thyroid reoperations can reduce the prevalence of RLN injury.

Methods This was a retrospective cohort study of patients who underwent thyroid reoperations with IONM versus with RLN visualization, but without IONM. The database of thyroid surgery was searched for eligible patients (treated in the years 1993-2012). The primary outcomes were transient and permanent RLN injury. Laryngoscopy was used to evaluate and follow RLN injury.

Results The study group comprised 854 patients (139 men, 715 women) operated for recurrent goiter $(n=576)$, recurrent hyperthyroidism $(n=36)$, completion thyroidectomy for cancer $(n=194)$ or recurrent thyroid cancer $(n=48)$, including 472 bilateral and 382 unilateral reoperations; 1,326 nerves at risk (NAR). A group of 306 patients (500 NAR) underwent reoperations with IONM and 548 patients (826 NAR) had reoperations with RLN
\end{abstract}

Presented at the 45th International Surgical Week, August 25-30, 2013, Helsinki, Finland.

M. Barczyński ( $₫)$ · A. Konturek · A. Papier · M. Stopa W. Nowak

Department of Endocrine Surgery, Third Chair of General Surgery, Jagiellonian University Medical College, 37 Pradnicka

Street, 31-202 Kraków, Poland

e-mail: marbar@mp.pl

K. Pragacz

Department of General Surgery, Public Health Care Medical

Center, 7811 Listopada Street, 28-200 Staszów, Poland visualization, but without IONM. Transient and permanent RLN injuries were found respectively in $13(2.6 \%)$ and seven $(1.4 \%)$ nerves with IONM versus $52(6.3 \%)$ and 20 (2.4\%) nerves without IONM ( $p=0.003$ and $p=0.202$, respectively).

Conclusions IONM decreased the incidence of transient RLN paresis in repeat thyroid operations compared with nerve visualization alone. The prevalence of permanent RLN injury tended to be lower in thyroid reoperations with IONM, but statistical validation of the observed differences requires a sample size of 920 NAR per arm.

\section{Introduction}

Thyroid reoperations can be challenging, even for a highly experienced thyroid surgeon, as visual identification of the recurrent laryngeal nerve (RLN) is more difficult during dissection of the scar tissues than in the virgin neck [1,2]. The prevalence of RLN injury is higher in repeat than in primary thyroid operations and it has been reported to approach $12.5 \%$ for transient events and $3.8 \%$ for permanent events [1-11]. Unilateral RLN injury can diminish quality of life due to a variety of symptoms related to voice changes and subsequent limitations in physical, emotional and social functioning, while bilateral RLN injury can be a life-threatening complication leading to airway obstruction [12]. Thus, it is not surprising that RLN injury is still a major cause of litigation in endocrine surgery [13]. In recent years, intraoperative nerve monitoring (IONM) has been standardized and has gained more acceptance as an addition to the gold standard of visual nerve identification in thyroid and parathyroid surgery [14-18]. IONM is believed by many surgeons to aid in RLN dissection in the scar tissues of the neck, minimizing the risk of inadvertent 
nerve injury [14]. However, so far, this belief is not evidence based [11]. A prospective randomised controlled trial of RLN visualisation versus RLN visualisation plus IONM in redo thyroid surgery is not readily feasible, justifying the use of evidence from cohort studies. The aim of the present retrospective cohort study was to test the hypothesis that the use of IONM in thyroid reoperations can reduce the prevalence of RLN injury in comparison with thyroid reoperations with RLN visual identification alone.

\section{Materials and methods}

This was a retrospective cohort study of patients who underwent thyroid reoperations at the Third Department of General Surgery, Jagiellonian University Medical College, Kraków, Poland. The prospectively collected database of thyroid surgery was searched for eligible patients (treated in the years 1993-2012). The study group comprised patients who underwent reoperative thyroid surgery with IONM. They were compared with patients who had thyroid reoperations with RLN visual identification, but without IONM. Laryngoscopy was mandatory in all patients before reoperation and afterwards, and was used to evaluate and follow RLN injury. All patients provided written informed consent for the storage and use of their data.

The inclusion criteria were recurrent goitre, recurrent hyperthyroidism, completion thyroidectomy for incidental cancer in a patient after bilateral less than near-total thyroidectomy (or Dunhill operation), or recurrent thyroid cancer. The exclusion criteria were contralateral goitre recurrence in a patient after lobectomy, completion thyroidectomy for cancer in a patient after lobectomy, goitre recurrence in the pyramidal lobe in a patient after total thyroidectomy or incomplete clinical data or follow-up information.

The primary outcome measures were transient and permanent RLN injury. The secondary outcome measures included the utility of IONM in mapping RLN in the scar tissues of the neck and in predicting postoperative vocal cord dysfunction: positive predictive value (PPV) and negative predictive value (NPV).

The protocol of this study was approved by the Institutional Review Board.

\section{Surgical technique}

Surgeon-performed neck ultrasound was mandatory in all patients before reoperation. It was used to identify the dominant side of goitre recurrence (which was operated on first), to identify if the pyramidal lobe remnant was present and to evaluate thyroid remnant volume and lymph node status.

All operations were performed on patients under general anaesthesia by five experienced endocrine surgeons (MB, AK, SC, MS, WN). The anaesthesia protocol included intravenous midazolam premedication; induction with fentanyl, thiopental and suxamethonium; endotracheal intubation and sevoflurane maintenance. No other muscle relaxants were used during the operations. A standard cervicotomy with excision of the existing scar was performed in all patients. A lateral approach was routinely used for all cases. In operations without IONM, the first step was visual identification of the RLN low in the neck (below the crossing with the inferior thyroid artery). Once the nerve was visually identified, it was carefully dissected along its course towards the larynx. In operations with IONM, the visual identification of the RLN was facilitated via the IONM system, with the nerve mapping technique. Once the nerve was visually identified, repeated stimulations with the monopolar probe of the IONM system served to trace the nerve path in the operative field and test its functional integrity during dissection. In each patient, the RLN was exposed and the branches of the superior and inferior thyroid arteries were divided close to the thyroid capsule (peripheral ligation). The characteristics of the patients are presented in Table 1, while the extent of surgery is presented in Table 2 .

Table 1 Characteristics of patients

\begin{tabular}{lll}
\hline Characteristics & $\begin{array}{l}\text { With IONM } \\
n=306\end{array}$ & $\begin{array}{l}\text { Without IONM } \\
n=548\end{array}$ \\
\hline Ratio (female:male) & $247: 59$ & $440: 108$ \\
Mean age \pm SD (years) & $54.6 \pm 13.2$ & $54.0 \pm 13.6$ \\
Preoperative diagnosis & & \\
Non-toxic multinodular goitre & $220(71.9)^{\dagger}$ & $356(65.0)^{\dagger}$ \\
Toxic multinodular goitre & $9(2.9)$ & $17(3.1)$ \\
Graves' disease & $2(0.7)$ & $8(1.5)$ \\
Differentiated thyroid cancer & $70(22.9)^{*}$ & $161(29.4)^{*}$ \\
Medullary thyroid cancer & $5(1.6)$ & $6(1.1)$ \\
Number of previous operations & & \\
1 & 258 & 485 \\
2 & 29 & 59 \\
3 & 1 & 4 \\
Preoperative RLN palsy $\lambda$ & $7(2.3)$ & $11(2.0)$ \\
\hline
\end{tabular}

Data are presented as numbers $(\%)$ unless otherwise indicated. $\lambda$ calculated for patients

$I O N M$ intraoperative nerve monitoring, $R L N$ recurrent laryngeal nerve, $S D$ standard deviation

${ }^{\dagger} p=0.038 ;{ }^{*} p=0.040$ all other differences were not significant 
Table 2 Extent of surgery

\begin{tabular}{|c|c|c|c|}
\hline & $\begin{array}{l}\text { With } \\
\text { IONM } \\
(n=306)\end{array}$ & $\begin{array}{l}\text { Without } \\
\text { IONM } \\
(n=548)\end{array}$ & $p$ value \\
\hline NAR & 500 & 826 & NA \\
\hline $\begin{array}{l}\text { Bilateral/unilateral dissections } \\
\text { (ratio) }^{\mathrm{a}}\end{array}$ & $\begin{array}{c}194 / 112 \\
(1.7)\end{array}$ & $\begin{array}{l}278 / 270 \\
(1.0)\end{array}$ & $<0.001$ \\
\hline \multicolumn{4}{|l|}{ Surgical intervention } \\
\hline Total thyroidectomy & $178(58.2)$ & $154(28.1)$ & $<0.001$ \\
\hline Near-total thyroidectomy & $12(3.9)$ & $56(10.2)$ & 0.001 \\
\hline $\begin{array}{l}\text { Bilateral subtotal } \\
\text { thyroidectomy }\end{array}$ & $4(1.3)$ & $68(12.4)$ & $<0.001$ \\
\hline Lobectomy & $110(35.9)$ & $201(36.7)$ & 0.831 \\
\hline Subcapsular lobectomy & $2(0.7)$ & $69(12.6)$ & $<0.001$ \\
\hline Central neck dissection & $31(10.1)$ & $48(8.8)$ & 0.507 \\
\hline Lateral neck dissection & $16(5.2)$ & $27(4.9)$ & 0.847 \\
\hline $\begin{array}{l}\text { Staged thyroidectomy in case } \\
\text { of } \operatorname{LOS} \lambda\end{array}$ & $23(7.5)$ & Not used & NA \\
\hline $\begin{array}{l}\text { Completion of staged } \\
\text { thyroidectomy in case of } \\
\text { LOS during first reoperation } \\
\lambda\end{array}$ & $11(3.6)$ & Not used & NA \\
\hline
\end{tabular}

Data are presented as numbers $(\%)$

$\lambda$ calculated for patients. $\chi^{2}$ test for all

IONM intraoperative nerve monitoring, LOS loss of signal on the dominant side (which was operated on first), NA not applicable, $R L N$ recurrent laryngeal nerve

a Patients with preoperative RLN paresis were calculated as unilateral dissections if contralateral side of the neck was operated on

IONM technique

During this study period, two differing neuromonitoring systems were used at our unit. The Neurosign ${ }^{\circledR} 100$ system (Inomed, Teningen, Germany) was in use between 2004 and 2007, while the $\mathrm{NIM}^{\circledR} 2.0$ followed by the $\mathrm{NIM}^{\circledR} 3.0$ (Medtronic, Jacksonville, USA) was in use between 2008 and 2012. The Neurosing ${ }^{\circledR} 100$ system operated with needle electrodes. After identification of the cricoid and thyroid cartilage, the ipsilateral vocal muscle was impaled with the bipolar recording electrode through the cricothyroid ligament. The neutral electrode was placed in the sternocleidomastoid muscle. The proper placement of the electrodes was confirmed by an impedance meter of the circuit in the patient in the final operating position. A handheld bipolar, concentric stimulating probe was used with a current amplitude of 1 (range 0.5-1.0) $\mathrm{mA}$ (depending on the RLN threshold) and 3-Hz impulses of $200 \mathrm{~ms}$ each for 1-2 s. The electrical field response of the muscle was documented as an acoustic signal. The NIM $^{\circledR}$ system operated with surface electrodes integrated with an endotracheal tube 7.0-7.5 in diameter, which was inserted by an anaesthetist between the vocal folds under direct vision during intubation. The standardized technique of neuromonitoring of the RLNs was used, including indirect vagal response evaluation at the beginning and at the end of the operation $(\mathrm{IONM}=\mathrm{L} 1+\mathrm{V} 1+\mathrm{R} 1+\mathrm{R} 2+\mathrm{V} 2+$ L2) according to the recommendations formulated recently by the International Intraoperative Neural Monitoring Study Group [14]. The nerves were stimulated using a monopolar electrode and the interrupted stimulation technique at $1 \mathrm{~mA}, 100 \mathrm{~ms}$ impulse duration and $4 \mathrm{~Hz}$ frequency. In case of bifurcated RLN nerves, the assessment included post-stimulation response of each nerve branch based on acoustic evaluation of the signal, EMG response evaluation (latency and amplitude) and the technique of posterior larynx palpation ('laryngeal twitch'). After the removal of the thyroid lobe, the indirect stimulation (through the electrode placed on the ipsilateral vagus nerve) response was determined and used to predict the postoperative outcome.

The validity of nerve monitoring was defined and calculated according to Chan and Lo [19]. A missing signal was considered positive, predicting postoperative ipsilateral vocal cord injury. The test result was regarded as true positive when ipsilateral RLN paresis was confirmed on a postoperative laryngoscopic examination and false positive when normal ipsilateral vocal cord function was found. An intact signal after the thyroidectomy was considered negative, predicting normal postoperative vocal cord function. This was interpreted as true negative if there was normal ipsilateral vocal cord function and false negative if there was a postoperative laryngoscopic diagnosis of RLN paresis.

Perioperative management and follow-up

Laryngoscopy (either indirect or direct videolaryngoscopy) by a throat specialist was mandatory before surgery and on day 1 after surgery. In patients with RLN paresis, an additional examination was scheduled at 1, 2, 4, 6 and 12 months after surgery, or until the vocal cord function was recovered. Vocal cord paresis for more than 12 months after the operation was regarded as permanent palsy.

Statistical analysis

For a sample size calculation, an assumption was made that the use of IONM as an addition to the gold standard of visual identification of the RLN should reduce the prevalence of RLN injury by $50 \%$ or more. To detect this, it was calculated that 492 nerves at risk (NAR) would be required in each treatment arm to give the study a power of $80 \%$ with $p=0.05$ to reliably evaluate RLN injury reduction from 6 to $3 \%$. The incidence of nerve events was calculated based on the number of NAR. Data are presented as 
Fig. 1 Year-to-year distribution of thyroid reoperations with respect to use of IONM among patients treated in 1993-2012. No IONM $(n=548)$, with IONM $(n=306)$

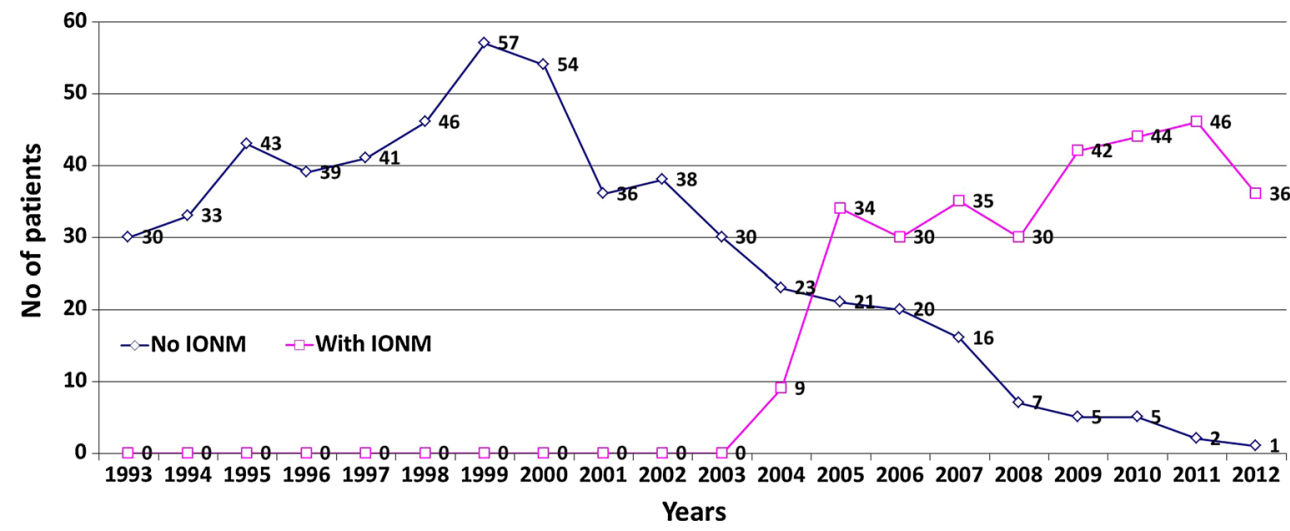

mean (standard deviation) or mean (range), unless stated otherwise. The statistical significance of categorical variables was evaluated using the $\chi^{2}$ test, whereas the Students $t$ test was used for the analysis of continuous variables. All data were collected prospectively, stored in a computerbased institutional register of thyroid surgery and analysed retrospectively by a statistician, assuming that $p<0.05$ was indicative of significance. Statistical analyses were performed with Statistica ${ }^{\circledR} 10$ for Windows ${ }^{\circledR}$ (StatSoft, Kraków, Poland).

\section{Results}

Of 15,383 patients referred for thyroid surgery during the study interval, 1,151 underwent reoperative thyroid surgery and were potential candidates for the study. A total of 297 patients did not meet the inclusion criteria (completion thyroidectomy for cancer in a patient after lobectomy 161 ; contralateral goitre recurrence in a patient after lobectomy 87 ; incomplete clinical data 23 or follow-up information 19 ; goitre recurrence in the pyramidal lobe in a patient after total thyroidectomy 7), leaving 854 patients who were finally included in this study. There were 715 women and 139 men, with a mean age at diagnosis of $54.2 \pm 13.4$ years. The IONM system became available at our unit in 2004 and, since then, it has been utilized in both primary and reoperative thyroid surgery with increasing frequency (Fig. 1). The study group comprised 306 patients (194 bilateral and 112 unilateral reoperations; 500 NAR) who underwent reoperative thyroid surgery with RLN visualization and IONM. The Neurosign ${ }^{\circledR} 100$ system (Inomed, Teningen, Germany) was used in reoperations of 108 patients treated in 2004-2007, while the $\mathrm{NIM}^{\circledR} 2.0$ followed by the $\mathrm{NIM}^{\circledR} 3.0$ (Medtronic, Jacksonville, USA) was used in reoperations of 198 patients treated in 2008-2012. A group of 548 patients (278 bilateral and 270 unilateral reoperations; 826 NAR) who had thyroid reoperations with RLN visualization but without IONM served as the control group. A clinical characteristics of the patients analysed in this study is shown in Table 1; the extent
Table 3 Incidence of RLN injuries

\begin{tabular}{lccc}
\hline $\begin{array}{l}\text { Postoperative } \\
\text { laryngoscopy }\end{array}$ & \begin{tabular}{l} 
NAR \\
With IONM \\
\cline { 2 - 3 }
\end{tabular} & $\begin{array}{l}\text { Without IONM } \\
(n=500)\end{array}$ & \\
\hline Paresis & & \\
Transient & $13(2.6)$ & $52(6.3)$ & 0.003 \\
Permanent & $7(1.4)$ & $20(2.4)^{\mathrm{a}}$ & 0.202 \\
Total paresis & $20(4.0)$ & $72(8.7)^{\mathrm{a}}$ & 0.001 \\
\hline $\begin{array}{l}\text { Data are presented as numbers }(\%) \\
\chi^{2} \text { test for all }\end{array}$ & & \\
$\begin{array}{l}\text { IONM } \\
\text { nerve }\end{array}$ & & \\
a Bilateral RLN palsy occurred in one patient with pre-existing \\
contralateral RLN palsy who underwent reoperation without IONM
\end{tabular}

of surgery is shown in Table 2. Both median and mean operative time was shorter for reoperations performed with versus without IONM ( 80 and $88.3 \pm 23.3 \mathrm{~min}$ vs. 100 and $94.5 \pm 23.0 \mathrm{~min} ; p<0.001)$.

Primary outcome measures analysis

In operations with RLN visualization plus additional IONM, the prevalence of RLN injury, transient RLN paresis and permanent RLN palsy was, respectively, $4.7 \%$ $(p=0.001), 3.7 \%(p=0.003)$ and $1.0 \%(p=0.202)$ lower than with visualization alone. At 12-month followup, 52 of 72 patients $(72.2 \%)$ having visualization alone versus 13 of $20(65.0 \%)$ individuals having additional IONM recovered their vocal cord function (median 4 months after surgery; range 2-12 months after surgery). Details are shown in Table 3. No bilateral RLN palsy occurred in patients reoperated with IONM, but it was a sequel necessitating tracheostomy in one patient with pre-existing contralateral RLN palsy who underwent reoperation without IONM ( 0 vs. $0.2 \%$, respectively; $p=0.455)$. 
Table 4 Correlation of IONM results with postoperative outcomes

\begin{tabular}{llllll}
\hline IONM $^{\text {a }}$ & \multicolumn{2}{l}{$\begin{array}{l}\text { Postoperative } \\
\text { outcome }(\mathrm{n})\end{array}$} & $\begin{array}{l}\text { Total } \\
(n)\end{array}$ & $\begin{array}{l}\text { Predictive } \\
\text { value }\end{array}$ & $\%$ \\
\cline { 2 - 3 } & $\begin{array}{l}\text { RLN } \\
\text { paresis }\end{array}$ & $\begin{array}{l}\text { No RLN } \\
\text { paresis }\end{array}$ & & & \\
\hline $\begin{array}{l}\text { LOS (positive) } \\
\begin{array}{l}\text { Intact signal } \\
\text { (negative) }\end{array}\end{array}$ & 18 & 5 & 23 & PPV & 78.3 \\
Total & 20 & 475 & 477 & NPV & 99.6 \\
\hline
\end{tabular}

Operations were performed with Neurosign ${ }^{\circledR} 100(n=108)$ and NIM 2.0 or NIM 3.0 systems $(n=198)$

Accuracy $\mathrm{TP}+\mathrm{TN} / \mathrm{TP}+\mathrm{TN}+\mathrm{FP}+\mathrm{FN}, \quad I O N M$ intraoperative nerve monitoring, $L O S$ loss of signal, $R L N$ recurrent laryngeal nerve, $P P V$ positive predictive value (TP/TP $+\mathrm{FP}), N P V$ negative predictive value $(\mathrm{TN} / \mathrm{TN}+\mathrm{FN}), T P$ true positive, $T N$ true negative, $F P$ false positive, $F N$ false negative

${ }^{a}$ Calculated for indirect stimulation through vagus nerve after thyroid resection (V2) and for NAR

Secondary outcome measures analysis

Utilization of the nerve mapping technique allowed for localization of 97 (19.4\%) of the RLN nerves before visual nerve exposition and almost twofold more ramified nerves than RLN visualization alone: 99/826 (12.0\%) versus $107 / 500(21.4 \%) ; p<0.001$. In addition, the non-RLN was identified in 9 of 500 NAR $(1.8 \%)$ operated with IONM versus 4 of $826(0.5 \%)$ NAR operated without IONM; $p=0.02$.

The value of IONM in predicting postoperative vocal cord function was encouraging. The following predictive values of the vagus stimulation (V2) at the end of surgery were found for the entire cohort of 500 NAR operated with IONM: NPV $99.6 \%$; PPV $78.3 \%$; and overall accuracy $98.6 \%$. Detailed data related to loss of signal predictive values are presented in Table 4. In our experience, the NIM 2.0 or NIM 3.0 systems had similar NPV and overall accuracy as the Neurosign ${ }^{\circledR} 100$ system (99.7 vs. $99.4 \%$ and 99.4 vs. $97.0 \%$, respectively), but better PPV (90.9 vs. $66.7 \%$, respectively).

\section{Discussion}

IONM has gained widespread acceptance as an adjunct to the gold standard of visual nerve identification, and this technique can be used to identify the RLN and the external branch of the superior laryngeal nerve (EBSLN) in both primary thyroid surgery and thyroid reoperations [11, 14, $15,18,20-23]$. The nerve may be mapped out in the operative field before visual identification, and additional intermittent stimulation of adjacent non-neural tissue versus nerve can help in tracing the nerve and all its branches through the dissected field. In addition, electric nerve testing at the end of the operation can serve for postoperative prognostication of nerve function [14]. In a prospective, randomized study of 1,000 patients $(1,000$ NAR per arm) published in 2009 by Barczyński et al. [17] the prevalence of transient RLN paresis was significantly lower in the group of patients who had primary thyroid surgery with IONM (by $2.9 \%$ in high-risk patients and by $0.9 \%$ in low-risk patients). The rate of permanent nerve palsy tended to be lower in operations performed with versus without IONM (by $30 \%$ ), but the power of this study was not sufficient to validate this difference. A more recent study by the same authors published in 2012 showed that the use of IONM significantly improved the identification rate of the EBSLN during thyroidectomy, as well as reduced the risk of early phonation changes after thyroidectomy [22, 23].

A reoperation in the scar tissue of the central neck is more dangerous for the RLN (and also for the parathyroid glands) than a primary operation, and the utilization of IONM is believed to aid in redo dissection, which should minimize the risk of nerve injury. It is well known that the prevalence of RLN injury after thyroid reoperations is variable (details are shown in Table 5) and dependent on surgeons' experience, and hence it is lower in high-volume centres [8, 24, 25]. Despite the fact that thyroid reoperations have become less common due to a wide acceptance of total thyroidectomy as a standard treatment for benign thyroid disease in tertiary referral centres, one-half of thyroid surgery worldwide is performed in low-volume centres, in which subtotal thyroidectomy is still a common procedure [25]. In recent years, the majority of patients undergoing thyroid reoperations in our unit were referred from outside low-volume institutions; $n=215$ of 306 patients $(70.3 \%)$ undergoing surgery with IONM in 2004-2012. Referring physicians recognized both the experience with and the availability of the IONM system at our institution as a guarantee of redo thyroid surgery being performed as safely as possible. However, so far, this belief is not entirely evidence based. It is well known that experience and routine nerve exposure are crucial to minimization of RLN complications [1, 2, 24, 25]. However, the IONMadded value in reducing RLN-related morbidity in the reoperative setting remains unclear. Yarbrough et al. [20] employed IONM in 52 cervical re-exploration procedures and found that it could be performed safely, but did not decrease RLN morbidity. Alesina et al. [11] recently reported a retrospective series of 250 thyroid reoperations, including 91 operations performed with IONM, and 159 surgeries with direct nerve visualization but without IONM, and no significant differences were observed in this study in the prevalence of RLN injury between both groups. Nevertheless, the outcomes of these studies could be influenced by selection bias, as decision to use IONM was dependent on the 
Table 5 RLN injury after reoperative thyroid surgery in published English-language series larger than 100 patients

\begin{tabular}{|c|c|c|c|c|c|}
\hline Author & Year & Patients $(n)$ & NAR $(n)$ & $\begin{array}{l}\text { Temporary RLN } \\
\text { injury }(\%)\end{array}$ & $\begin{array}{l}\text { Permanent RLN } \\
\text { palsy }(\%)\end{array}$ \\
\hline Reeve et al. [1] & 1988 & 408 & nd & $6(1.5)^{\mathrm{a}}$ & nd \\
\hline Levin et al. [2] & 1992 & 114 & nd & $1(0.9)^{\mathrm{a}}$ & $1(0.9)^{\mathrm{a}}$ \\
\hline Seiler et al. [3] & 1996 & 166 & 242 & nd & $10(4.1)$ \\
\hline Chao et al. [4] & 1997 & 115 & nd & $3(2.6)^{\mathrm{a}}$ & $2(1.7)^{\mathrm{a}}$ \\
\hline Menegaux et al. [5] & 1999 & 202 & nd & $5(2.5)^{\mathrm{a}}$ & $2(1.0)^{\mathrm{a}}$ \\
\hline Müller et al. [6] & 2001 & 949 & 1,307 & $46(3.5)$ & $33(2.5)$ \\
\hline Gibelin et al. [7] & 2004 & 122 & nd & $15(12.3)^{\mathrm{a}}$ & $1(0.8)^{\mathrm{a}}$ \\
\hline Lefevre et al. [8] & 2007 & 685 & nd & $8(1.2)^{\mathrm{a}}$ & $10(1.5)^{\mathrm{a}}$ \\
\hline Calò et al. [9] & 2012 & 106 & 174 & $5(2.9)$ & $1(0.6)$ \\
\hline \multirow[t]{2}{*}{ Kurmann et al. [10] } & 2012 & 109 & 133 ipsilateral & nd & $5(3.8)$ \\
\hline & & & 33 contralateral & nd & $0(0)$ \\
\hline \multicolumn{3}{|c|}{ RLN injury without vs. with IONM } & $\begin{array}{l}\text { Without vs. } \\
\text { with IONM }\end{array}$ & $\begin{array}{l}\text { Without vs. } \\
\text { with IONM }\end{array}$ & $\begin{array}{l}\text { Without vs. } \\
\text { with IONM }\end{array}$ \\
\hline Alesina et al. [11] & 2012 & 246 & 161 vs. 128 & $4(2.5)$ vs. $8(6.2)$ & $1(0.6)$ vs. $0(0)$ \\
\hline Present study & 2013 & 836 & 826 vs. 500 & $52(6.3)$ vs. $13(2.6)^{\ddagger}$ & $20(2.4)$ vs. $7(1.4)$ \\
\hline
\end{tabular}

Data are presented as numbers $(\%)$ unless otherwise indicated

Calculation for NAR unless otherwise indicated

IONM intraoperative nerve monitoring, $n d$ no data, $R L N$ recurrent laryngeal nerve

$* p=0.003$

${ }^{\text {a }}$ Calculation for patients, not for NAR

availability of the equipment and individual surgeon's preferences according to the planned extent of the surgical procedure (a more liberal use of IONM in more challenging dissections). On the other hand, these studies were based on relatively small groups of patients, and statistical validation of small differences in the prevalence of RLN injury requires much bigger study arms.

As indicated by the results of our power calculation, 492 NAR are required in each treatment arm to give the study a power of $80 \%$ with $p=0.05$ to reliably evaluate RLN injury reduction from 6 to $3 \%$. The present study is the largest comparative analysis of thyroid reoperations performed with versus without IONM. It is important to stress that the prevalence of transient RLN paresis was decreased by almost $60 \%$ in operations with RLN visualization plus additional IONM than RLN visualization alone (2.5 vs. $6.3 \%$, respectively; $p=0.003$ ). In addition, the prevalence of permanent RLN palsy was $40 \%$ lower in reoperations with IONM than with RLN visualization alone, but this difference was statistically not significant $(p=0.202)$. Given the outcomes of this study, a sample size of 920 NAR per arm was calculated as required to reliably assess the difference in the prevalence of permanent RLN events.

The explanation of better outcomes achieved in thyroid reoperations with IONM versus RLN visual identification alone should include a few important issues. First, IONM provided improved recognition of the anatomical details in the scar tissues of the neck with the use of the nerve mapping technique (almost $20 \%$ of the RLNs were identified with IONM before visual exposition of the nerve, and almost twofold more ramified nerves were identified in reoperations with IONM). In addition, the rare but particularly prone to injury non-RLN was almost fourfold more often identified in patients operated with versus without IONM $(p=0.02)$. A lack of the initial vagus response (V1) when stimulating below the inferior thyroid artery, but positivity when stimulating above the inferior thyroid artery in a patient with intact preoperative ipsilateral vocal cord mobility, and a latency of the response shorter than $3.5 \mathrm{~ms}$ may alert the surgeon to the occurrence of this rare variant of the nerve before any surgical dissection is undertaken. This technique is of paramount importance in avoiding inadvertent and in most cases unrecognized intraoperative injury to the non-RLN [26, 27]. Second, intermittent RLN stimulation during the operation allowed for functional testing of the nerve. In case of EMG amplitude decrease during the case amounting to a drop of more than 30-50\% from the baseline value, even if the RLN seemed to be anatomically intact, surgeons stopped the dissection for a while and continued it with reduced traction of the nerve, observing in most cases a spontaneous EMG signal recovery. Third, in case of a loss of signal on the dominant side of the neck, which was, as a rule, operated on first (defined as no EMG signal at all, or a 
weak EMG waveform amplitude of less than $100 \mu \mathrm{V}$ after ipsilateral vagus stimulation), the contralateral thyroid reoperation was staged for both benign $(n=20)$ and malignant disease $(n=3)$. Contralateral thyroid surgery was undertaken afterwards when ipsilateral vocal fold mobility was restored $(n=11)$. Two patients refused to undergo completion thyroidectomy after staged procedure for loss of signal. Details are shown in Tables 2, 3 and 4. In general, contralateral thyroid surgery was avoided in patients with benign thyroid disease and the only functioning RLN (permanent palsy), but it was undertaken in selected patients with contralateral loco-regional recurrence of thyroid cancer. The concept of staged thyroidectomy was proven to be effective in preventing bilateral RLN injury [28, 29], which is particularly important in bilateral thyroid reoperations and has been accepted by many [18, 30], but not all, thyroid surgeons [31]. The opponents of staged thyroidectomy indicate that PPV of IONM is relatively low (varying from 50 to $75 \%$ in the majority of reported series), which can result in unnecessary staging of operation in $25-50 \%$ of patients who experience loss of signal on the first side, but have no ipsilateral RLN paresis [31]. In this study, PPV of IONM was within the upper limits of the reported values (see Table 4), and it was better for the systems based on EMG waveform analysis $(90.9 \%)$ than for simple nerve stimulators with acoustic signalling $(66.7 \%)$. Thus, further improvements in PPV can be expected with utilization of continuous IONM, based on automatic permanent stimulation of the vagus nerve and almost real-time monitoring of the EMG quantitative parameters during surgery [32]. It should be also recognized that a cost-effectiveness analysis of the routine utilization of IONM in thyroid reoperations has never been reported and was also out of scope for this study; this issue needs to be clarified in future.

In conclusion, in our hands, IONM decreased the incidence of transient RLN paresis in repeat thyroid operations as compared with nerve visualization alone. The prevalence of permanent RLN injury tended to be lower in reoperations with IONM. However, given the outcomes of this study, a sample size of 920 NAR per arm is required to reliably assess a difference in the prevalence of permanent RLN events. Experience and routine nerve exposure remain crucial to the minimization of RLN complications in thyroid reoperations, but the use of the lateral approach with mapping of the RLN low in the neck and tracing its path in the scar tissues towards the larynx may provide additional benefits: an improved recognition rate of the ramified or non-recurrent nerves, and functional RLN testing feedback alerting the surgeon to a possible stretching injury of the nerve, particularly in the region of the ligament of Berry [33].
Acknowledgments No extra funding was awarded for research or publication.

Open Access This article is distributed under the terms of the Creative Commons Attribution License which permits any use, distribution, and reproduction in any medium, provided the original author(s) and the source are credited.

\section{References}

1. Reeve TS, Delbrige L, Brady P et al (1988) Secondary thyroidectomy: a 20-year experience. World J Surg 12:449-453. doi:10. 5542/LJS.v3i0

2. Levin KE, Clark AH, Duh QY et al (1992) Reoperative thyroid surgery. Surgery 111:604-609

3. Seiler CA, Glaser C, Wagner HE (1996) Thyroid gland surgery in an endemic region. World J Surg 20:593-596. doi:10.1210/er. 2002-0016

4. Chao TC, Jeng LB, Lin JD et al (1997) Reoperative thyroid surgery. World J Surg 21:644-647. doi:10.4174/jkss.2013.85.3.104

5. Menegaux F, Turpin G, Dahman M et al (1999) Secondary thyroidectomy in patients with prior thyroid surgery for benign disease: a study of 203 cases. Surgery 125:479-483

6. Müller PE, Jakoby R, Heinert G et al (2001) Surgery for recurrent goiter: its complications and their risk factors. Eur J Surg 167:816-821

7. Gibelin H, Sierra M, Mothes D et al (2004) Risk factor for recurrent nodular goiter after thyroidectomy for benign disease: case-control study of 224 patients. World J Surg 28:1079-1082. doi:10.1007/s00268-004-7607-x

8. Lefevre JH, Tresallet C, Leenhardt L et al (2007) Reoperative surgery for thyroid disease. Langenbeck Arch Surg 392:685-691

9. Calò PG, Pisano G, Medas F et al (2012) Risk factors in reoperative thyroid surgery for recurrent goitre: our experience. G Chir 33:335-338

10. Kurmann A, Herden U, Schmid SW et al (2012) Morbidity rate of reoperation in thyroid surgery: a different point of view. Swiss Med Wkly 142:w13643. doi:10.4414/smw.2012.13643

11. Alesina PF, Rolfs T, Hommeltenberg S et al (2012) Intraoperative neuromonitoring does not reduce the incidence of recurrent laryngeal nerve palsy in thyroid reoperations: results of a retrospective comparative analysis. World J Surg 36:1348-1353. doi:10.1007/s00268-012-1548-6

12. Smith E, Taylor M, Mendoza M et al (1998) Spasmodic dysphonia and vocal fold paralysis: outcomes of voice problems on work-related functioning. J Voice 12:223-322

13. Abadin SS, Kaplan EL, Angelos P (2010) Malpractice litigation after thyroid surgery: the role of recurrent laryngeal nerve injuries, 1989-2009. Surgery 148:718-722

14. Randolph GW, Dralle H, International Nerve Monitoring Study Group (2011) Electrophysiologic recurrent laryngeal nerve monitoring during thyroid and parathyroid surgery: international standards guideline statement. Laryngoscope 121(Suppl 1):S1S16

15. Dralle H, Sekulla C, Lorenz K et al (2008) Intraoperative monitoring of the recurrent laryngeal nerve in thyroid surgery. World J Surg 32:1358-1366. doi:10.1007/s00268-008-9483-2

16. Chan WF, Lang BHH, Lo CY (2006) The role of intraoperative neuromonitoring of recurrent laryngeal nerve during thyroidectomy: a comparative study on 1000 nerves at risk. Surgery 140:866-873 
17. Barczyński M, Konturek A, Cichoń S (2009) Randomized clinical trial of visualization versus neuromonitoring of recurrent laryngeal nerves during thyroidectomy. Br J Surg 96:240-246

18. Dralle H, Sekulla C, Lorenz K et al (2012) Loss of the nerve monitoring signal during bilateral thyroid surgery. Br J Surg 99:1089-1095

19. Chan WF, Lo CY (2006) Pitfalls of intraoperative neuromonitoring for predicting postoperative recurrent laryngeal nerve function during thyroidectomy. World J Surg 30:806-812. doi:10. 1007/s00268-005-0355-8

20. Yarbrough DE, Thompson GB, Kasperbauer JL et al (2004) Intraoperative electromyographic monitoring of the recurrent laryngeal nerve in reoperative thyroid and parathyroid surgery. Surgery 136:1107-1115

21. Chiang FY, Lu IC, Tsai CJ et al (2011) Does extensive dissection of recurrent laryngeal nerve during thyroid operation increase the risk of nerve injury? Evidence from the application of intraoperative neuromonitoring. Am J Otolaryngol 32:499-503

22. Barczyński M, Konturek A, Stopa M et al (2012) Randomized controlled trial of visualization versus neuromonitoring of the external branch of the superior laryngeal nerve during thyroidectomy. World J Surg 36:1340-1347. doi:10.1007/s00268-0121547-7

23. Barczyński M, Randolph GW, Cernea CR et al (2013) External branch of the superior laryngeal nerve monitoring during thyroid and parathyroid surgery: international neural monitoring study group standards guideline statement. Laryngoscope 123(Suppl 4):S1-S14. doi:10.1002/lary.24301

24. Hermann M, Alk G, Roka R et al (2002) Laryngeal recurrent nerve injury in surgery for benign thyroid diseases: effect of the nerve dissection and impact of individual surgeon in more than 27000 nerves at risk. Ann Surg 235:261-268

25. Barczyński M, Konturek A, Stopa M et al (2011) Total thyroidectomy for benign thyroid disease - is it really worthwhile? Ann Surg 254:724-730
26. Brauckhoff M, Machens A, Sekulla C et al (2011) Latencies shorter than $3.5 \mathrm{~ms}$ after vagus nerve stimulation signify a nonrecurrent inferior laryngeal nerve before dissection. Ann Surg 253:1172-1177

27. Donatini G, Carnaille B, Dionigi G (2013) Increased detection of non-recurrent inferior laryngeal nerve (NRLN) during thyroid surgery using systematic intraoperative neuromonitoring (IONM). World J Surg 37(1):91-93. doi:10.1007/s00268-0121782-y

28. Goretzki PE, Schwarz K, Brinkmann J et al (2008) The impact of intraoperative neuromonitoring (IONM) on surgical strategy in bilateral thyroid diseases: is it worth the effort? World J Surg 34:1274-1284. doi:10.1007/s00268-009-0353-3

29. Melin M, Schwarz K, Lammers BJ et al (2013) IONM-guided goiter surgery leading to two-stage thyroidectomy-indication and results. Langenbecks Arch Surg 398:411-418

30. Dionigi G, Frattini F (2013) Staged thyroidectomy: time to reconsider intraoperative neuromonitoring a standard of care. Thyroid 23(7):906-908. doi:10.1089/thy 2013.0004

31. Sitges-Serra A, Fontané J, Dueñas JP et al (2013) Prospective study on loss of signal on the first side during neuromonitoring of the recurrent laryngeal nerve in total thyroidectomy. Br J Surg 100:662-666

32. Schneider R, Randolph GW, Sekulla C et al (2012) Continuous intraoperative vagus nerve stimulation for identification of imminent recurrent laryngeal nerve injury. Head Neck. doi: 10. 1002/hed.23187

33. Chiang FY, Lu IC, Kuo WR et al (2008) The mechanism of recurrent laryngeal nerve injury during thyroid surgery: the application of intraoperative neuromonitoring. Surgery 143:743749 